\title{
CODE SWITCHING AND CODE MIXING IN ENGLISH LANGUAGE STUDIES' SPEECH COMMUNITY: A SOCIOLINGUISTICS APPROACH
}

\author{
Ni Nyoman Wartinah \\ wartinaninyoman@gmail.com \\ University of Batam \\ Chrisda N. Wattimury \\ chrisdawattimury@gmail.com \\ Sanata Dharma University
}

\begin{abstract}
Enormously complex and not well understood are some state of affairs for a bilingual to 'change' the use of language from one to another when having conversation with other bilinguals in daily conversation. This linguistics behavior of changing the language, or widely known as language switching' and 'language mixing', leads the researchers to find out the trigger behind this phenomenon. After done a research on Malaysian pre-school students, Karen Kow (2003) proposed some reasons of doing code switching and code mixing namely lack of one word in either language, to avoid misunderstanding, to make a point, etc. However, students of graduated students of English Language Studies of Sanata Dharma University can be categorized as bilingual or multilingual since they employ two even many languages in the daily conversation in their speech community. Therefore, by taking 12 students of $A$ class as the subject of the research through random sampling method, the discussion of this research will focus on investigating the reasons of both code switching and code mixing.
\end{abstract}

Keywords: code switching, code mixing, reason, bilingual, speech community

\section{Introduction}

Language is an integral part of life and an integral part of the social system. Many scholars have reflected on the important of language in teaching and learning process, where English becomes a formal language in classroom context. Basically, language is being used by human to communicate with other to convey meaning. Meaning can be both written and spoken. According to Holmes (2011), people will not be able to get involve with their surrounding without language. Thus, language becomes very important since all processes of response and communication express through language. However, people usually speak differently in different social contexts in which concerns the identification of language social function and the ways it is used to convey social meaning. And again, the important thing to be remembered is that before having interaction with other, people have to consider the language choice in certain speech community.

Considering that language serves a range of function, as the outcome, people may become bilingual either by acquiring two languages at the same time. Often the first language is the language they master before acquiring the second language. As stated by Nordquist (2009), "a bilingual person is someone who speaks two languages". Bilinguals may appear in multilingual communities where the speakers speak multilanguage at the same time. The continuation of bilingual or multilingual communities is deliberately possible to trigger the employing of code switching and code mixing in interaction process. Further, Aranoff (2001: 530) stated many worlds of the bilingual or multilingual communities that are fluent by bilingualism 
sometimes engage in code switching and code mixing by producing discourses in the same conversational turn or in consecutive turns.

Referring to this circumstance, the researchers are interested in exploring the use of code switching and code mixing from a sociolinguistics approach standpoint. Holmes (2001) affirmed sociolinguistics deals with a study of how languages are used by certain society or speech community. For more detail, Hudson (1996) defined sociolinguistics as the study of language in operations, its purpose is to show the conventions of language use relate to other aspect of culture. Thus, what a sociolinguistics approach wants to see is about the language to use, to who people speak, and what the aim of communication.

As bilinguals, Sanata Dharma University students, specifically students majoring English Language Studies, frequently execute the code switching and code mixing by accommodating more than one language in their speaking. Hoffman (1991:106) stated code switching is the switching of language from its smallest units, starting from words, phrases, clauses, and sentences. Meanwhile, even the code mixing term is different from the code switching, they are still related one another. To point this, Hudson (1996: 53) explained code mixing as a king of linguistics cocktail where it consists of a few words of one language, few words of the other, then back to the first for a few words and so on. To make it clear, Swann (2004) summarized the notion of code switching and code mixing refers to the instances when the speakers switch codes (language or language varieties) in the course of conversation that may involve different amounts of speech and different linguistics units from several consecutive utterances to individual words and morphemes. Hence, both the code switching and code mixing deal with the language choice according to the circumstances, where in bilingual/ multilingual community, different language are always used in different intention to convey meanings.

However, each person possibly has different reason of using code switching and code mixing his/ her own. Based on the researchers' perspective, the general reason is that the language will be more comprehensible to the person addressed, so the speakers choose a language which the other can understand. In aiming to uncover the reasons of English Language Studies students in employing code switching and code mixing, theoretically, the researchers refer to Karen Kow (2003) who listed some possible conditions on this. Some of the conditions proposed by Kow are lack of one word in either language, some activities have only been experienced in one of the language, some concepts are easier to express in one of the language, a misunderstanding has to be clarified, one wishes to create certain communication effect, one continues to speak the language latest used because of the trigger effect, one wants to make a point, one wishes to express group solidarity, and one wishes to exclude another from the dialogue.

Conversely, the previous research done by Karen Kow (2003) investigated Preschool Malaysian students found that the use of code switching and code mixing is a highly innovative strategy employed by Malaysian children to convey meaning, which involves the use of words taken from L1. The major condition initiated the children to change their language was the lack of knowledge matter. Nevertheless, lack of knowledge suggests that a child uses a word she or he is not familiar with because of his/her incomplete and limited vocabulary knowledge. However, in doing communication with others with English, the child tries hard to get his/her meaning across while talking about concepts she or he has as yet no words for. It can be concluded that their purpose in doing code switching and code mixing is because they want to express meaning within the limits of his/her competence in the target language. 


\section{Research Method}

To answer the problem above, the researchers apply both qualitative and quantitative method. Through combining these two methods, the researchers intend to gain reliability and to provide deeper and richer description on findings. Kaplan (2000) stated the combination of qualitative and quantitative methods allow statistically reliable information obtained from numerical measurement to be backed up by and enriched by information about the research participants' explanations to grant a richer and contextual basis for interpreting and validating results. Thus, through random sampling method the researchers took 12 students majoring on English Language Studies program, considered as bilingual/ multilingual community, by applying nonparticipant observation and questionnaire method to gather the data. Methodologically, the non-participant observation was conducted in form of four weeks classroom observation, started from October 6 to November 5, 2015 and the questionnaires were spread in the last day of observation dated November 5, 2015. Both methods focus on finding reasons of doing code switching and code mixing in classroom interaction, and after the data was gathered, to make it easy, the researchers organize and divide the data into several categories in table form then analyze them.

\section{Discussion}

As bilingualism, ELS students potentially attach to the usage of more than one language when interact with others. In dealing with different occasions and circumstances, they possibly adjust or change the language use needed to communicate. One of the alternatives may emerge from this situation is the using of code switching and code mixing when they challenge to apply English as the necessitated language in class room interaction. The following are the results of the researchers' investigation about the code switching and code mixing in ELS speech community.
Table 1

Results of Non-participant Observations for the Reason of English Language Studies Students in Doing Code Switching and Code Mixing

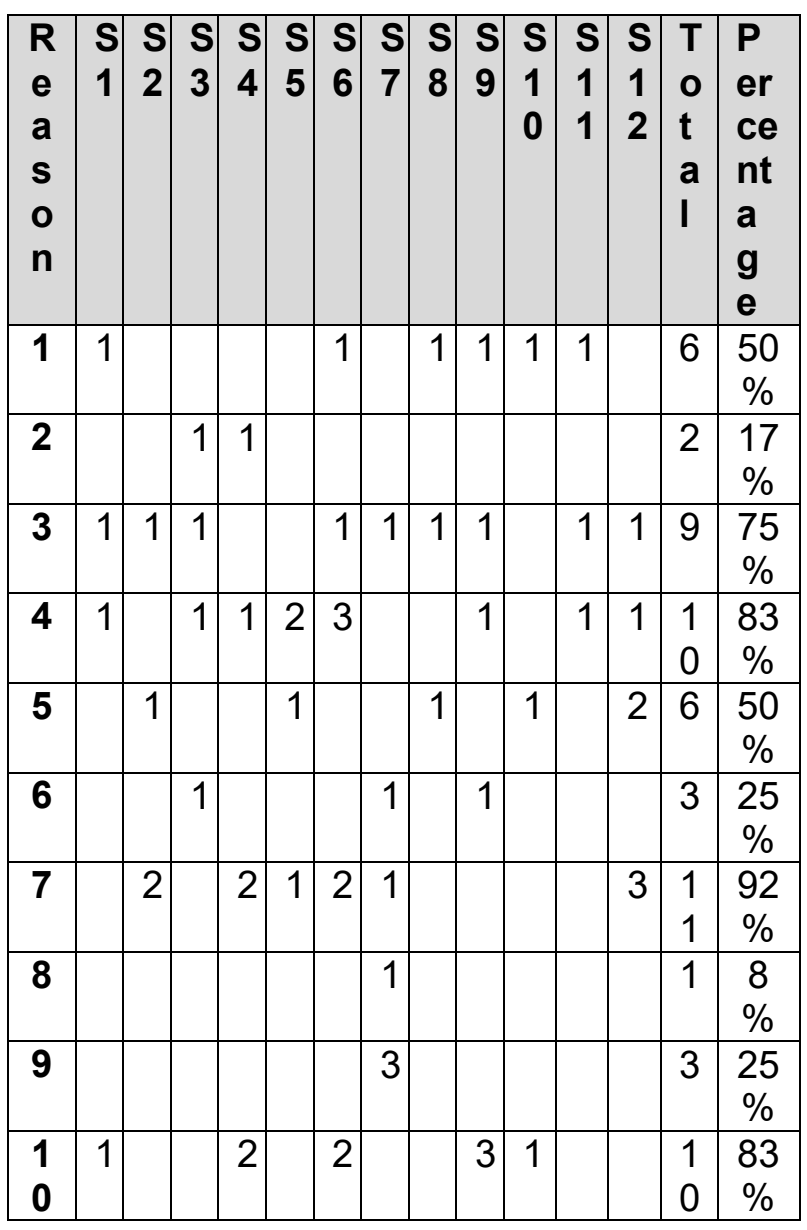

Table 2

Results of Questionnaire for the Reason of English Language Studies Students in Doing Code Switching and Code Mixing

\begin{tabular}{|c|l|l|c|c|}
\hline $\mathbf{N}$ & \multicolumn{2}{|c|}{ The Indication } & $\begin{array}{c}\text { Tot } \\
\text { al }\end{array}$ & $\begin{array}{c}\text { Percenta } \\
\text { ge }\end{array}$ \\
\hline 1 & $\begin{array}{l}\text { The } \\
\text { reasons } \\
\text { of doing } \\
\text { code } \\
\text { switchin } \\
\text { g and }\end{array}$ & $\begin{array}{l}\text { Reason } \\
1\end{array}$ & 7 & $58 \%$ \\
\cline { 2 - 4 } & $\begin{array}{l}\text { Reason } \\
\text { Reason }\end{array}$ & 2 & $17 \%$ \\
\hline
\end{tabular}




\begin{tabular}{|c|c|c|c|c|}
\hline & \multirow[t]{6}{*}{$\begin{array}{l}\text { code } \\
\text { mixing }\end{array}$} & $\begin{array}{l}\text { Reason } \\
4\end{array}$ & 10 & $83 \%$ \\
\hline & & $\begin{array}{l}\text { Reason } \\
5\end{array}$ & 8 & $67 \%$ \\
\hline & & $\begin{array}{l}\text { Reason } \\
6\end{array}$ & 2 & $17 \%$ \\
\hline & & $\begin{array}{l}\text { Reason } \\
7\end{array}$ & 11 & $92 \%$ \\
\hline & & $\begin{array}{l}\text { Reason } \\
8\end{array}$ & 1 & $8 \%$ \\
\hline & & $\begin{array}{l}\text { Reason } \\
9\end{array}$ & 3 & $25 \%$ \\
\hline \multirow[t]{7}{*}{2} & \multirow[t]{7}{*}{$\begin{array}{l}\text { Other } \\
\text { reasons }\end{array}$} & $\begin{array}{l}\text { Sentence } \\
\text { fillers }\end{array}$ & 5 & $42 \%$ \\
\hline & & $\begin{array}{l}\text { Talking } \\
\text { about } \\
\text { particular } \\
\text { topic }\end{array}$ & 8 & $67 \%$ \\
\hline & & $\begin{array}{l}\text { Creating } \\
\text { humor }\end{array}$ & 4 & $33 \%$ \\
\hline & & $\begin{array}{l}\text { Mood of } \\
\text { speaker }\end{array}$ & 4 & $33 \%$ \\
\hline & & $\begin{array}{l}\text { Habitual } \\
\text { expressi } \\
\text { on }\end{array}$ & 7 & $58 \%$ \\
\hline & & $\begin{array}{l}\text { Quoting } \\
\text { somebod } \\
\text { y else }\end{array}$ & 3 & $25 \%$ \\
\hline & & & & \\
\hline
\end{tabular}

\section{Note:}

Reason 1: lack of one word in either language

Reason 2: some activities have only been experienced in one of the language

Reason 3: some concepts are easier to express in one of the language

Reason 4: a misunderstanding has to be clarified

Reason 5: one wishes to create certain communication effect

Reason 6: one continues to speak the language latest used because of the trigger effect

Reason 7: one wants to make a point

Reason 8: one wishes to express group solidarity

Reason 9: one wishes to exclude another person from the dialogue

Reason 10: other reasons
In general, the concepts suggested by Karen Kow theoretically fix the reasons of ELS students in using code switching and code mixing in their speech community. Among nine reasons of Kow, all of the reasons are used by the ELS students. Here the results are: lack of one word in either language $(50 \%$ to $58 \%)$, some activities have only been experienced in one of the language $(17 \%)$, some concepts are easier to express in one language (75\% to $83 \%$ ), a misunderstanding has to be clarified (83\%), one wishes to create certain communication effect e.g. get audience's attention (50\% to $67 \%)$, one wants to make a point (92\%), one continues to speak the language latest used because of the trigger effect (17\% to $25 \%$ ), one wishes to express group solidarity $(8 \%)$, and one wishes to exclude another person from the dialogue (25\%).

As seen in the Table.1 and Table.2, it can be compared the result between the non-participant observation and the questionnaire of reason for doing code switching and code mixing employed by English Language Studies students, especially A class batch 2015 , is quite similar. Obviously, the two tables display the major reason to do code switching and code mixing is the seventh reason, in accordance with the purpose that student wants to make a point. This dominant reason occupies $92 \%$, which point the highest number among others. Both from the observation and the questionnaire show students often do code switching and code mixing to make point about certain things in order to make a clear statement or explanations. Meanwhile, based on her research, Karen Kow stated that the major reason of Malaysian children in her research to do code switching and code mixing is the lack of vocabulary. However, what the researchers find in ELS speech community may suggest that graduated students of Sanata Dharma University have acquired enough knowledge in using English, so the lack of vocabulary is no longer become the major problem in their communication, intentionally when they 
have to communicate with other students or even lecturers with English.

On the other hand, back to Karen Kow previous research, Malaysian children never use the intention to exclude another person from the dialogue as reason in doing code switching and code mixing, since in fact, they are still in very young age and have innocent way of thinking and communicating with others. Meanwhile, from the observation and the questionnaire, the researchers locate that this sort of reason occupies $25 \%$ among the ELS students. As the example, student 7 tends to switch and mix the language out of two languages used in speech community discourse by speaking Javanese to exclude the other students who do not belong to Javanese speech community, for example the one comes from Papua or Bali.

Besides the nine reasons proposed by Karen Kow, the researchers found that ELS students of Sanata Dharma University employ different reasons in using code switching and code mixing. These reasons may be affected by the mood of the speakers when they speak. Here are some other reasons found in ELS students' speech community:

\section{a. Sentence fillers}

Code switching and code mixing are also attributed as sentence fillers. In relation with sentence fillers matter, ELS students often do code switching and code mixing to fill the empty or silent moment between the utterances they produce while speaking. This can be in form of repeated word like saying "apa?", "emmm" or "aaaa" for many times. Through this alternative way, the speakers may have another second to think about words they are going to say in the following dialogue, thus switching the code or the language may be an approachable technique to do to keep the continuity of the communication. From the table, this reason occupies $42 \%$ of the other reason to apply code switching and code mixing in ELS students' conversation.

\section{b. Talking about particular topic}

Sometimes in talking about particular topic, people tend to use a more relevant or valid language especially in dealing with culture and tradition cases. As a fact, ELS students of A class majorly come from Java Island where some languages are easier to express in Javanese language. The researcher found talking about particular topic takes $67 \%$ of the reason in employing code switching and code mixing in interacting with others. This reason may use to avoid the misunderstanding, since sometimes we do not find appropriate language or term to say, when we try to translate the source language to the target language. One of the examples found in ELS speech community is when students talk about specific jargon or slogans of the institutions, where the speakers keep the words' originality (in Bahasa Indonesia terms) to prevent the misconception of the listeners.

\section{c. Creating humor}

Code switching and code mixing are also intended to create humorous situations in order to reduce students' tension in formal class situation. Thus, to create a livelier and to break the situation in the classroom, ELS students frequently change the language to Bahasa Indonesia or even Javanese. They choose to use the Bahasa Indonesia or Javanese to create humor instead of English to make sense of what message they want to convey. In fact, ELS students are all Indonesian students, therefore, they feel more comfortable and feel close to their first language (Bahasa Indonesia or Javanese). One of the students creates a joke in Javanese language by saying "Mbok ya kita ada study tour ke Cina". This statement rises as a feedback to break the rigid situation during the 
teaching and learning process in the class. It is seen form the table that this reason occupies 33\% related to the ELS students' intention of doing code switching and code mixing.

\section{d. Habitual expression}

In this term, people may not aware that they often employ certain language habitually. Code switching and code mixing often occur in fixed phrases of greeting, parting, commands and request, invitation, expression of gratitude and discourse markers (Malik, 1994). In addition, the switching may also occur influenced by the speaker moods, such as feeling nervous. This case happens in ELS speech community, as what stated before, they are Javanese in general. The researchers find that some students, especially Javanese ones, prone to use Javanese language such as "Sik" which in English means "Wait" when they get stuck in some points during the class interaction. Thus, by switching the language, here the speakers may express that certain language can become his/her habit to use that language more often in their daily speaking. Based on the table, we can see that this matter takes $58 \%$ of reason why students switch and mix their language in the conversations.

\section{e. Quoting somebody else}

In doing the presentation, theoretically the academic one, it is the compulsory requirement to make both the presentation and the paper in a scientific way. Thus, students have to quote some sources to strengthen their idea about the discussed issue. To quote means the students have to find some references, in this case not only English, the Bahasa Indonesia quotations may also possible to get the original idea, further they have to provide the translation in English version of course. ELS students when have to deal with Cultural Study course, in case of finding and doing research on the closest culture that the students may experience, sometimes the students have to use the Indonesian references as the sources of their writing. Here, the aim of quoting somebody else places $25 \%$ of ELS students' reason to do code switching and code mixing.

\section{Conclusion}

From the findings above, it can be figured that the using of code switching and code mixing strategy may be view as a selective strategy. Through the changing of language, this can be an innovative strategy that confirms the creativity of students in the area of meaning making. Both code switching and code mixing are the functional strategy that is used to convey a message in an efficient and effective way. The researchers found that English Language Studies students of Sanata Dharma University have different reasons in employing the switching and mixing code in the classroom interaction. The result shows that Karen Kow's theory of doing code switching and code mixing, the nine reasons, are generally found in ELS students interaction, meanwhile, the researchers also find other reasons out of nine proposed by Kow, such as sentence fillers, talking about particular topic, creating humor, habitual expressions, and quoting somebody else. However, the thing should be underlined related to this phenomenon, whatever the purpose and strategy they had, the students were able to create an innovative and creative way to communicate with others through using more than one language at the same time in their speech community. 


\section{REFERENCES}

Aranoff, M. (2001). The Study of Language. Cornwell: Blackwell Publishing.

Hoffman, C. (1991). An Introduction to Bilingualism. New York: Longman.

Holmes, J. (2001). An Introduction to Sociolinguistics. New York: Longman Group.

Hudson, R.A. (1996). Sociolinguistics. Melbourne: Cambridge University Press.

Kaplan, B. (2000). “Combining Qualitative and Quantitative Methods". In http://eprints. sussex.ac.uk/1498/01/combining_quantitative_and_qualitative_methods.pdf. Retrieved on 19 October 2015.

Karen, K. Y. C. (2003). "Codeswitching for a Purpose: Focus on Preschool Malaysian Children". Multilingua, p.59-77.

Malik, L. (1994). Sociolinguistics: A Study of Code Switching and Code Mixing. New Delhi: Anmol.

Swann, J. (2004). A Dictionary of Sociolinguistics. Edinburgh: Edinburgh University Press.

http://www.sfs.unituebingen.de/ dm/04/spring/201/ bilingualism.pdf. Retrieved on 26 October 2015. 